OPEN ACCESS

Edited by:

Kevin Surprise,

Mount Holyoke College, United States

Reviewed by:

Danielle Young,

University of the Ozarks, United States

Miranda Boettcher,

Institute for Advanced Sustainability

Studies (IASS), Germany

${ }^{*}$ Correspondence:

Shannon O'Lear

olear@ku.edu

tThese authors have contributed equally to this work

¥These authors have contributed equally to this work and share last

authorship

Specialty section:

This article was submitted to

Climate Risk Management,

a section of the journal

Frontiers in Climate

Received: 01 June 2021

Accepted: 06 August 2021

Published: 16 September 2021

Citation:

O'Lear S, Hane MK, Neal AP, Stallings LLM, Wadood S and Park J (2021) Environmental Geopolitics of Climate Engineering Proposals in the IPCC 5th Assessment Report.

Front. Clim. 3:718553.

doi: 10.3389/fclim.2021.718553

\section{Environmental Geopolitics of Climate Engineering Proposals in the IPCC 5th Assessment Report}

\author{
Shannon O'Lear ${ }^{1 *}$, Madisen K. Hane ${ }^{2 \dagger}$, Abigail P. Neal ${ }^{2 \dagger}$, Lauren Louise M. Stallings ${ }^{3+}$, \\ Sierra Wadood ${ }^{2 \ddagger}$ and Jimin Park ${ }^{4 \ddagger}$
}

${ }^{1}$ Department of Geography and Atmospheric Science, Environmental Studies Program, University of Kansas, Lawrence, KS, United States, ${ }^{2}$ Environmental Studies Program, University of Kansas, Lawrence, KS, United States, ${ }^{3}$ Environmental Studies Program, School of Journalism and Mass Communications, University of Kansas, Lawrence, KS, United States, ${ }^{4} \mathrm{Global}$ and International Studies Program, Political Science Department, University of Kansas, Lawrence, KS, United States

Environmental geopolitics offers an analytical approach that considers how environmental themes are brought into the service of geopolitical agendas. Of particular concern are claims about environment-related security and risk and the justification of actions (or inactions) proposed to deal with those claims. Environmental geopolitical analysis focuses on geographical knowledge and how that knowledge is generated and applied to stabilize specific understandings of the world. Climate engineering is a realm in which certain kinds of geographical knowledge, in the form of scientific interpretations of environmental interactions, are utilized to support a selective agenda that, despite claims about benefiting people and environments on a global scale, may be shown to reinforce uneven relationships of power as well as patterns of injustice. This paper focuses on how the IPCC AR5 discusses and portrays climate engineering. This particular conversation is significant, since the IPCC is widely recognized as reflecting current, international science and understanding of climate change processes and possible responses. We demonstrate an initial, environmental geopolitical analysis of this portrayal and discussion around climate engineering proposals by observing how the role and meaning of environmental features is limited, how human agency and impact in these scenarios is selective, and how insufficient attention is paid to spatial dimensions and impacts of these proposals. This paper contributes to a larger conversation about why it matters how we engage in discussion about climate impacts and issues; a central argument is that it is vital that we consider these proposed plans in terms of what they aim to secure, for whom, how and where.

Keywords: geoengineering, geopolitics, security, risk, critical geopolitics, IPCC

\section{INTRODUCTION}

There is widespread realization that humans have altered the planet, unintentionally, through farreaching applications of technologies. One response to that realization is to suggest that humans re-alter the planet, intentionally, through far-reaching applications of different technologies. The general label for such responses is climate engineering or geoengineering. Two main categories of 
technologies have generated much discussion and some research (Shepherd, 2009, 2012; Sovacool, 2021). Carbon Dioxide Removal (CDR) technologies aim to capture $\mathrm{CO}_{2}$ as a greenhouse gas and remove it from the atmosphere by trapping or storing it in vegetation, deep underground, or human-constructed chambers built for this purpose. The idea is that removing heat-trapping gas from the atmosphere will slow the rising temperature of the atmosphere where these gases from human activity are collecting. Another category of climate engineering approaches is Solar Radiation Management (SRM) which aims to reflect incoming solar radiation before it enters the atmosphere. CDR technologies are thought to be more effective over time, depending on the form of storage. SRM technologies could mask some effects of climate change but require intensive maintenance to avoid lapses of abrupt warming; neither technology would be a feasible, stand-alone alternative to mitigation of atmospheric warming (Vaughan et al., 2011).

These technologies, their impacts, and their implications are not fully understood. There are concerns that research on these technologies has been limited to physical science and an instrumental view instead of considering them as having societal effects and justice implications in terms of who might benefit or be rendered vulnerable by these technological deployments (Markusson et al., 2020). There have been calls for better integration of social sciences and humanities in efforts to assess risk associated with climate change (Lemos et al., 2020), yet it has also been recognized that merely adding layers or variables of social science onto research that is structured by physical sciences overlooks and obscures other ways of approaching or defining a situation (Demeritt, 2009). These critiques relate to climate engineering technologies which are based largely on selective, calculative models.

For instance, there is a question if models of aerosol engineering have adequately considered not only the economic cost of periods of abrupt warming, but also the intergenerational costs of long-term impacts of this atmospheric moderation (Goes et al., 2011). Other scholars have made the case that technologies such as SRM are inherently expensive and currently pursued by an elite group of powerful people in ways that are undemocratic (Szerszynski et al., 2013; Stephens and Surprise, 2020), that prioritize earth system interactions and reduce humans to mere static (Wiertz, 2016), and that risk being swept up by unilateral or military interests out of claims to security (Surprise, 2020). More broadly, climate engineering of any kind, "involves an understanding of the earth as a geoengine that can be altered, modified, and engineered on a global scale" (Yusoff, 2013). That kind of view of the world is fraught with assumptions about geopolitical decision making. In conversations about climate engineering, scientific organizations themselves become influential actors in political processes. Even though scientists are divided on the feasibility and usefulness of these technologies, the fact that IPCC Working Groups are considering geoengineering technologies signals that these options may be theoretically viable, regardless of the fact that the IPCC is not formally endorsing them.

By not questioning the direction and implications of the conversation on climate engineering explicitly, researchers contribute to the continued entrenchment of the status quo and a growing disparity between winners and losers in the decisionmaking process (Castree et al., 2014). The shape and tone of the scientific conversations themselves are important indicators of what kinds of knowledge and perspective they include as well as what they leave out. There is more to proposed climate engineering technologies than the physical alterations they could bring about. There are political implications, societal impacts, and questions about what kind of environments we can create and who gets to decide. The technologies are only part of the story, but they are neither the question nor the complete answer.

We offer an analysis of how climate engineering is portrayed by the IPCC and why it matters. Even though the IPCC is not designed to make policy recommendations, how it portrays knowledge about climate engineering matters given the IPCC's central role and internationally recognized position in conveying knowledge about the dynamics of the changing climate. In this paper, we offer an environmental geopolitics analysis of how the IPCC portrays geoengineering technologies in its Fifth Assessment Report in an effort to make visible geopolitical power dynamics of this conversation. "Whenever an argument connects an environmental feature to some form of risk or security, there is an excellent opportunity to examine the situation for what it reveals (or conceals) about claims to power and place" (O'Lear, 2020 , p. 194). The analytical framework of environmental geopolitics allows a critical assessment of how certain kinds of geographic knowledge are prioritized through a three-fold focus on the selective portrayal of environmental features, human systems, and spatial scale. Any portrayal of something as complex as our changing planetary circumstances is necessarily incomplete. An environmental geopolitics analysis provides a framework to understand nuances of the incompleteness and to make visible the kinds of knowledge that are foregrounded as well as what views or perspectives are missing from the conversation. Here, we are less concerned with the agency or influence of individual scientists working within the IPCC structure (although see Hamilton, 2014). Instead, we consider the IPCC as an influential organization that serves to communicate scientific understanding-in selective ways-to decision makers. How the IPCC includes information about climate engineering is literally a matter of world making and how the planetary environment could be intentionally altered through actions taken and actions not taken. This paper contributes to a larger conversation about why it matters how we engage in discussion about climate engineering; a central argument is that it is vital that we consider the IPCC's treatment of these ideas in terms of what they aim to secure, for whom, how and where.

\section{ENVIRONMENTAL GEOPOLITICS}

We use an environmental geopolitics framework (O'Lear, 2018), summarized in this section, because this analytical approach allows a multidimensional view of the knowledge politics underlying-and driving-conversations about climate engineering in the academic and policy realms. Environmental geopolitics encourages us to examine and question assumptions 
on which claims about climate engineering, in the form of CDR and SRM research, are built. An environmental geopolitics assessment of climate engineering proposals and how they could arguably work and offer certain benefits allows insights into ways in which these claims are also selective and limited in terms of justice and security. As an analytical framework, environment geopolitics allows the examination of claims about climate engineering as more than scientific assessments; these claims are also a conversation about who has the power to make decisions about how scientific practices could be employed to alter the living spaces and conditions for human and nonhuman populations.

Environmental geopolitics draws from work in critical geopolitics, an area of work that examines political claims about places and spaces to discern the assumptions underlying those claims. Critical geopolitics recognizes that there is no single, universal way of understanding how the world works but that there are multiple, simultaneous perspectives. Any portrayal of the world (Dalby, 1991; O' Tuathail and Agnew, 1992) or claims about risk or security are necessarily selective and incomplete. In short: "A critical approach questions how pieces of information are strung together to make an argument, and it also considers what kinds of information may be missing from an argument or explanation. A critical stance also questions how an explanation is focused" (O'Lear, 2020, p. 195). Of interest to critical geopolitics is how a given portrayal or explanation may serve particular interests over others either explicitly or, more likely, implicitly.

Environmental geopolitics adopts the same, critical stance of examining the promotion of selective geographic knowledge, but the focus is specifically on claims about environmental features (O'Lear, 2018, 2019, 2020). Environmental geopolitics operationalizes the idea that, "There is a geopolitics to how environmental problems are represented" (Castree, 2003 p. 427). Claims about environmental features as valuable, as a threat, as requiring action or inaction, embed particular forms of knowledge and power in how those claims are formed and how they are communicated. These claims become political when they are promoted by speakers in a position to motivate action, when they are used to persuade people to act in certain ways, and when they serve to enact decisions about who gets what, when, how (Lasswell, 1937) and where.

This environmental geopolitics framework is particularly helpful in assessing claims about environment-related security and risk. A traditional approach to security centers on military threats to a territorial state and is defined by clear boundaries between "Us" and "Them" (or, between whatever is being prioritized and everything else) (see O'Lear, 2018 Ch. 4). More recently, critical security studies has questioned the power dynamics implicit in how boundaries around security are drawn and how priorities are established. "What is being secured and for whom?" (Dalby, 2009) is a question that gets to the underbelly of what security means. Security for one group of people may leave other groups of people quite insecure (Barnett, 2001). Labeling a concern a security issue tends to prioritize it and justify actions that are outside of or beyond politics as normal (Buzan et al., 1998; Huysmans, 1998; Peoples and Vaughan-Williams, 2015).
Looking at issues that have been labeled as security concerns, it is helpful to assess why an issue has been prioritized and who will benefit from the heightened importance of that issue (Walker, 1987).

Risk is also a complex concept. Beck (1992) recognized how technologies may bring progress to society, but they tend to bring unintended and uncontrollable risks or negative impacts. "Risks," Beck noted in his later work, "are always future events that may occur, that threaten us. But because this constant danger shapes our expectations, lodges in our heads and guides our actions, it becomes a political force that transforms the world" (Beck, 2009, 9-10). Calculating risks in quantitative terms can provide a sense of clarity around a particular risk or threat, but data and numbers can impart a false sense of confidence. Amoore (2014) considers how, by not publicly acknowledging the fallibility of mathematical science as one of many possible approaches to problem solving, "the public space for critique and dissent is closed out" (p. 436). Additonally, it matters how we perceive risk. How we interpret numbers that represent damage are critical for understanding risk and how it shapes public actions (Slovic, 2016). Both security and risk are concepts that tend to generate a desire for clarity and certainty, and they are both inherently slippery. These two concepts will serve as touchstones in this assessment of climate engineering proposals in the IPCC AR5 through an environmental geopolitics analysis.

An environmental geopolitics approach (O'Lear, 2018, pp. 59) pays attention to how certain geographic knowledge is elevated by considering three key observations about any political claim about the environment:

\section{The Role and Meaning of the Environment Are Rarely Specified}

Claims about environmental problems may portray environmental features in narrowly defined terms or as isolated from complex interactions. Although focusing selectively on a particular feature or process may be necessary for understanding that feature or process, ultimately it cannot be fully understood in isolation from a broader context of interactions. Scientific measures of an environmental feature are a selective representation of the feature itself. A reductive view of perspectivalism accepts that there is a definite and knowable reality "out there" that may be objectively described by science. A wider view of fractionality, however, accepts that there are multiple ways of understanding "truth" (Mol, 2002; Law, 2004). Science, then, is not so much a direct representation of reality but a work of composition: "Science, conceived as a situated work of composition, is necessarily political, separating what is taken into account from what is not" (Goeminne, 2010, p. 211). How, for instance, should we measure the health of an ecosystem: on the basis of what that ecosystem would have been like before human influence, or on the basis of how resilient that ecosystem is in the context of interaction with humans (Blue and Tadaki, 2019)? In either case, the science applied to the question may be robust, but what really matters is how the starting point is defined by the question that is being asked about the environment. 


\section{Humans' Role or Agency in These Situations Tends to Be Considered Selectively. In Particular, Dynamics of Power Remain Invisible and Un-investigated}

Political claims about environmental features or processes tend to link them to stability or instability or to security or insecurity. The link is not necessarily explicit. Concerns about increased droughts, floods, or less predictable environmental circumstances of any sort are not so much about the environmental feature itself but about how that feature could impact human systems such as agricultural productivity, infrastructural integrity, human tensions over access to resources, and the like.

In the case of climate change and possible responses to it, a dominant focus of current narratives is impacts of climate change rather than the human factors contributing to those changes. By omitting consideration of the globespanning economy powered by fossil fuel, it is easier to focus on the changing environment as the threat, not the human systems that brought us to this point. Solutions, then, are focused more on addressing and altering environmental features, and less on the human systems that set up the problem. The solutions themselves draw from the very same approaches to the world-economic assessments, governance proposals, and territorial-based statecraft-that generated the current conditions in the first place (O'Lear and Dalby, 2016, p. 3). Despite the unprecedented nature of climate change [or, as Scientific American has recently acknowledged: climate emergency (Fischetti, 2021)], we have continued to respond through the familiar approach of modernity. A key feature of modernity's response to climate change is a management stance that aims to "fix" the climate through the application of science and technology (Glover, 2016). Such a promotion of science and technology as a means to conquer or master the environment reflects not only the idea that humans are separate and apart from "nature"; it also sits precariously close to a value system that separates people into groups worth protecting and others who are deemed disposable or not worth protecting. References to humanity on a global scale may suggest some sort of shared responsibility and uniform experience, but such ideas are misleading (Gemenne, 2015). They overlook how industrialization and colonization have generated and continue to perpetuate significant differences in well-being. Ideas of a "global humanity" obscure the reality that people have not benefited equally from the modern, global economy and that the vulnerability of many groups of people could be worsened by practices that serve to reinforce current arrangements of power and decision making (Hamilton et al., 2015).

Narratives or claims about the environment may not seem overtly political. For that reason, it is all the more critical to examine them carefully for what they acknowledge and what they disregard about human agency and the distribution of power.

\section{Claims About Environmental Features or Problems Tend to Be Set Within a Particular Spatial Scale. How the Problem or Feature Is Connected to Other Spatial Scales, Patterns, or Processes May Be Overlooked by This Spatial Focus}

It is understandable that we tend to pay attention to the spatial scale where a problem appears the most clearly. Attention is often focused according to the spatial scale of available data or at the spatial scale where an environmental feature or interaction is most evident. Rigorous inquiry often demands clear boundaries in order to concentrate on a particular focus. In order to situate any inquiry into a cohesive, geographic understanding, however, it is necessary to consider how the feature or interaction in question is related to patterns and processes at other spatial scales. A relationship within an ecosystem, for instance, could be explained by microbial processes. Microbes, in turn, may be connected to larger patterns of dispersion beyond the ecosystem. A fuller understanding of any environmental process considers not only how that process is associated with human systems and agency, as noted above, but also how that process is connected to other spatial scales.

Zooming in or zooming out, as it were, from a particular spatial understanding of a given environmental concern can be informative. Yet, we often accept without question the spatial terms in which an environmental problem or feature is portrayed. What insights may be available to us when we approach the spatial scale of a problem or claim with curiosity? By seeing how a problem and its solution are framed spatially, we can examine how that relationship has other influences at smaller scales, at larger scales, and through connections to other places. For instance, we can understand many things about Arctic ice melt by studying the Arctic region, but it is also important to understand the larger context of the changing climate as well as smaller scale aspects such as the ability of some flora and fauna to adapt. Similarly, it is important to consider the anticipated impacts of a decision on the spatial scale immediately impacted by the decision, but it is also valuable to consider how that decision will likely have impacts on other spatial scales as well. Taking this observation seriously contributes to a more comprehensive, geographic understanding of the problem or relationship in question.

These three observations provide a useful way to unpack arguments that link environmental features to risk or to security so that it is more clear who is benefitting from this claim-who is telling this story? - and how different places and groups of people might be affected. Such an examination makes it possible to identify assumptions embedded in these arguments and to see a broader context and deeper implications of these kinds of arguments.

The next section considers the IPCC and its role as a scientific organization. Following a brief methodology sections, we then consider how the IPCC AR5 Working Group reports portray climate engineering proposals for CDR and SRM. In three sections structured around the key observations of 
environmental geopolitics, we offer a critical analysis not only of these particular claims about how to approach a given problem, but about how the conversation about climate engineering, as a whole, is portrayed by the IPCC and how notions of security and risk appear to propel that conversation in particular directions.

\section{THE IPCC-AN OVERVIEW}

The IPCC was first established in 1988, and has been subject to scholarly critique since its inception. In its initial years, the group was positioned largely within the hard sciences, prompting scholars to critique the marginalization of the social sciences by the body in its reports (Redclift, 1992; Cohen et al., 1998; Malone and Rayner, 2001). In response, the IPCC began adding in perspectives from social sciences in later reports (Hulme and Mahony, 2010), beginning with the inclusion of Working Group III in the second Assessment Report published in 1995, whose report was titled "Economic and Social Dimensions of Climate Change." In more recent reports, the majority of social science research has been compiled by Working Group II, which has produced reports on "Impacts, Adaptation, and Vulnerability" beginning with the Third Assessment Report in 2001. The IPCC has since become a key voice in the global discussion of climate change; its reports and recommendations have become the foundation for policy decisions worldwide, and its conclusions set the framework for which actions are even considered. The most recent Fifth Assessment Report (AR5), includes three working group reports on climate science, impacts, and mitigation strategies, published in 2013 and 2014. The Sixth Assessment Report is scheduled to be released in 2022.

The IPCC's history of prioritizing the natural sciences erases perspectives offered by research in disciplines beyond the physical sciences. This hierarchical approach to different disciplines which places the social sciences and humanities in a subsidiary role continues into the most recent reports (Hulme and Mahony, 2010). Since analysis focuses primarily on the technical aspects of climate systems and responses and does not fully explore the human and political impacts, these perspectives and concerns are outside of the boundaries of discussion set by IPCC publications. This trend was demonstrated in research by Hiramatsu et al. (2008), which found that the aspects of climate change receiving the least attention by the IPCC were "socioeconomic activity and greenhouse gas emissions," adaptation, and social systems-the aspects on which the social sciences and humanities are most focused and have most to contribute. The limited inclusion of research from outside the hard sciences should also be subject to critique. Even when effort is made to incorporate "human dimensions" into physical science, few mentions of "power, violence, inequality, and the perennial desire of some people to replace one socio-environmental regime with an entirely different one" (Castree et al., 2014, p. 765). This tendency is reflected in the disproportionate representation of economics research in the context of social science papers identified by Bjurström and Polk (2011), creating the impression that the IPCC believes the most relevant social science is economics. This prioritization serves to further marginalize actual social sciences and the perspectives they bring to climate research (Yearley, 2009).

It is important that the IPCC has come to be considered as the preeminent communicator of climate science to the world of politics. Beck and Mahony (2018) consider the challenges that this relationship between the IPCC and the ear of policymakers presents. They note that the IPCC has moved from serving as a seemingly "objective" assessment of projected impacts of global warming into a politically powerful entity that is shaping the very conversation about human response to global warming. The IPCC prioritizes the knowledge, research, and editorial preferences of politically powerful nations. This "geography of IPCC expertise" has been explored throughout decades of research, and affects the way that IPCC emissions scenarios are created, the way knowledge about climate change is framed, and the perceived legitimacy of the IPCC's assessment reports (Parikh, 1992; Shackley, 1997; Hulme and Mahony, 2010; O’Neill et al., 2010). The hierarchies of knowledge present throughout science are replicated in the process of determining which research is included in full Assessment Reports, which is obscured, and which is included in summaries used by technical professionals and policymakers. The process of condensing thousands of pages of research into brief summaries is contentious and political, and representatives of national governments have power to go through summaries line-by-line to approve or strike certain findings. Research cannot be stricken from full reports by government representatives, but findings not included in the shorter summaries will likely never reach the eyes of policymakers that are responsible for translating reports into action. A specific example of this process is the deletion of a fourth of the figures included in a draft summary for policymakers at request of government representatives that viewed the information in the figures as "politically inconvenient" (Victor et al., 2014).

The IPCC tends to portray itself as an objective, unbiased organization that compiles and summarizes facts. However, scholars of science and technology studies have argued that the process of knowledge production and determination of scientific "truth" is inherently political and fraught with bias (Jasanoff, 1996; Bijker, 2001). Attempts to depoliticize even natural science and technical research are flawed because science is inherently political. Furthermore, Castree et al. (2014) have made the case that depoliticization, or the non-acknowledgment that something is inherently political, limits what can be considered and closes off alternate pathways for action and interpretation. The IPCC in particular displays significant bias in terms of the prioritization of the natural or physical sciences and even in the prioritization of the interests of some states over others (O'Lear, 2016).

The very fact that the IPCC produces its Summaries for Policymakers is an acknowledgment that the organization is no longer simply a voice of scientific objectivity. "Boundary work," which is defined as the "ideological efforts by scientists to distinguish their work and its products from non-scientific intellectual activities," (Gieryn, 1983, p. 782) has been considered part of the dynamic relationship between scientific neutrality and politics. One could argue that the IPCC operates as a boundary organization due to the production of "boundary objects" in its 
Summaries for Policymakers and Annual Reports. For example, the rhetoric of temperature targets like 2 degrees $\mathrm{C}$ or 1.5 degrees $\mathrm{C}$ are considered boundary objects because they can be considered scientific findings, but with tangible and political policy recommendations and implications for implementation (Beck and Mahony, 2018). The interaction between science and policy is often a paradox, because while policy-relevant scientific information about climate is highly sought after, prescriptive climate science results in an almost impossibleto-avoid politicization. Shaw (2005) argues that there is a conflict within the IPCC's Summaries for Policymakers between maintaining "objectivity" in its findings and also creating "policy relevance' for policymakers. What is more, the IPCC's reliance on "certainty-calibrated qualifiers of confidence" has been critiqued, and "the tone of the IPCC's probabilistic language is remarkably conservative" (Herrando-Pérez et al., 2019, p. 209). In such efforts to avoid appearing too politicized, the IPCC effectively undersells realities and challenges of climate change, which in itself is a politicization. It creates political openings for organizations and actors with an interest in maintaining the status quo. Protecting the science boundary in effect politicizes the science.

The depoliticization of the IPCC, as evidenced by its attempts to position itself as an objective, policy-neutral, scientific body (Pearce et al., 2018) obscures the political motivations behind its actions, legitimizing existing political hierarchies and structures and entrenching them into the very foundation of the global response to climate change. Since the countries, actors, and ways of knowing that already drive global conversations on policy also have outsize representation in working groups, they exercise political influence on the kinds of research included in IPCC reports. As these power structures are further depoliticized under the guise of objective science, they become a baseline of the models designed to guide global responses to climate change. The fact that the IPCC AR5 includes any consideration of SRM and CDR technologies lends the credibility and status of the IPCC to these areas of research. The AR5 does not include a clear statement of approval or discouragement of geoengineering research and development, and its vague treatment of geoengineering has led to conflicting interpretations. The purpose of this paper is to consider the representation of climate engineering technologies in the IPCC AR5 and view it through the lens of environmental geopolitics.

\section{METHODOLOGY: AN ENVIRONMENTAL GEOPOLITICS OF CLIMATE ENGINEERING IN THE IPCC AR5}

The following sections apply the three, key observations of the environmental geopolitics framework to the treatment of climate engineering in the IPCC Fifth Assessment Report (AR5). Using the word search feature and terms such as "climate engineering," "geoengineering," "CDR," and "SRM," a search of each of the three IPCC Working Group reports that make up the AR5 was conducted to identify passages discussing climate engineering. The technical reports were not included. The Summaries for Policy Makers do not include sufficient material on proposed climate engineering methods for a meaningful analysis (a point which, in itself, raises questions about the extent to which these proposed technologies are either not considered viable for policy consideration or are not being made visible to policy-relevant discussions). The discussion below captures trends in how the IPCC Working Group Reports discuss climate engineering technologies. In several instances, direct passages discussing climate engineering are included for the purpose of assessing how the scientific narrative relates to geopolitical relationships and power dynamics. Throughout the analysis, security and risk serve as touchstones to assess the tone and positioning of these proposed technologies in the IPCC AR5.

\section{The Role and Meaning of Environment}

The first entry point of an environmental geopolitics analysis of a political claim about the environment takes a critical look at how the particular environmental feature is defined and understood. This approach to environmental features invites curiosity about how environmental features or processes may be simplified, separated, measured and otherwise interpreted through particular ontologies or ways of knowing. By examining the selective portrayal of environmental features, it is possible to see what kinds of knowledge are prioritized in the claim about the environment and what other kinds of knowledge are not considered or not valued. Both of these avenues of inquiry offer insights to how the claim about the environment may be suited to particular agendas and exclusive of other views.

The emergence (Petersen, 2018) and treatment of climate engineering in IPCC reports, specifically the Fifth Assessment Report (AR5), has already been the subject of controversy and critique (Parker and Geden, 2016; Beck and Mahony, 2018; Reynolds, 2021). Baskin (2019) has traced how the topic of geoengineering moved from taboo to being a topic for consideration first as an emergency response and then, eventually, as an economically efficient, pre-emptive approach to climate change. In particular, Baskin pieces together the emergence of geoengineering in climate science and policy circles through a stepwise series of publications and reports with varying degrees of confidence and enthusiasm for these technologies. He notes the sharp contrast in tone about geoengineering between earlier assessment reports from the IPCC, which were dismissive of geoengineering, to the AR5 which includes consideration in all three working group reports and the summary for policymakers (p. 91).

The report produced for the AR5 by Working Group I (WGI), “The Physical Science Basis" (IPCC, 2013), offers this summary:

CDR methods could provide mitigation of climate change if $\mathrm{CO}_{2}$ can be reduced, but there are uncertainties, side effects and risks, and implementation would depend on technological maturity along with economic, political and ethical considerations. CDR would likely need to be deployed at largescale and over at least one century to be able to significantly reduce $\mathrm{CO}_{2}$ concentrations. There are biogeochemical, and currently technical limitations that make it difficult to provide quantitative estimates of the potential for CDR...The level of confidence on the effectiveness of CDR methods and their side effects on carbon and other biogeochemical cycles is low (p. 98). 
Even less optimistically, the report further states: "SRM remains unimplemented and untested but, if realizable, could offset a global temperature rise and some of its effects....Limited literature on other SRM methods precludes their assessment" (p. 98). Additionally, this report recognizes that there are likely other "unanticipated consequences" (p. 98) of these technologies. Given this rather bleak outlook on the two most known climate engineering technologies from the Working Group most focused on the physical science of the changing climate, there seems to be little reason to pursue the topic of climate engineering. However, a table in Ch. 6 of the WGI report provides an overview of various forms of CDR. In Ch. 7 of the WGI report, a discussion of SRM notes that these technologies are thought to carry risks such as uneven, regional changes in rainfall patterns and polar stratospheric ozone depletion. Interestingly, in a comparison to other human-environmental feature that interact with clouds and albedo, this section of the report notes that, "The lack of clear evidence for a global increase in cloud albedo from ship tracks and volcanic plumes should be borne in mind when considering geoengineering methods that rely on cloud modification" ( $p$. 610). This section of the report discusses how aerosol particle size and reflectivity would change over time, the possibility of high latitude ozone depletion, the level of risk of acid precipitation, ocean acidification, and scenarios for land surface temperature change across regions and diurnal cycles while other impacts have not been sufficiently studied that they may be quantified. This Working Group report, then, demonstrates that what is known from a physical science perspective about CDR and SRM leaves those technologies questionable in terms of the promise they might hold to reverse some of the changes already happening. The report also recognizes several parameters or variables that are insufficiently understood to justify confidence in either technology.

The report from Working Group II, "Impacts, Adaptation, and Vulnerability," (IPCC, 2014a,b) considers impacts and implications of climate engineering ideas. Table 6.5, "Challenges for the oceans that will arise from the employment of a range of geoengineering methods" (p. 455), summarizes how SRM and CDR deployments are expected to generate biogeophysical reactions, alter ocean acidification levels, and cause localized variation in gasses and minerals. Other impacts that are anticipated but that have not been measured include impacts from mining and crushing large amounts of silicate minerals that would be needed for SRM.

Chapter 6 of the Working Group III report, "Mitigation of Climate Change" (IPCC, 2014c) spends a few pages summarizing the state of knowledge about SRM techniques that aim to alter the earth's solar radiation budget rather than the level of heat-trapping greenhouse gases in the atmosphere. Even if SRM techniques could reduce the global mean surface air temperature, they would not bring the global mean hydrological cycle intensity to pre-industrial conditions. Model simulations of SRM deployments, in fact, suggest that these technologies would likely alter global hydrological conditions in uncertain ways such as regional precipitation patterns. One reason is that these technologies would not alter $\mathrm{CO}_{2}$ levels in atmosphere which, "directly affects the opening of plant stomata, and thus the rate of transpiration of plants and in turn the recycling of water over continents, soil moisture, and surface hydrology" (p. 487). SRM technologies are anticipated to have non-climatic effects such as negative effects on stratospheric ozone and the efficiency of solar powered energy systems.

This overview of how the IPCC AR5 includes and portrays climate engineering illustrates how physical science calculations and models dictate how "the" environment is understood. In these discussions of climate engineering, none of which goes into significant detail, the focus, particularly in the WGI report, is on specific physical systems and interactions. Environmental features are narrowly specified for specific calculations (e.g., cloud brightening and albedo measurements, calculations of $\mathrm{CO}_{2}$ storage capacity and chemical changes in the atmosphere, predictions of ocean acidification and localized changes in precipitation patterns), or they are discussed in broad terms (e.g., large scale deployments of CDR technologies over the course of a century). The environment is considered in mechanistic ways focused on processes that can be measured or analyzed with scientific methodologies.

In these Working Group reports, the environment is understood predominantly through the lens of established, physical science practices. The discipline of physics has been dominant in how climate change has been defined and understood (Von Storch et al., 2011), and computer models have enabled the generation of "global" data sets and an idea of a global climate (Edwards, 2010). Scientific methodologies dictate how different forms of data come to be accepted as representations of particular aspects of the world (Van Fraassen, 2008 cited by Lloyd, 2012) to the point, sometimes, as being mistaken for those realities themselves. Climate science and, more specifically, proposed technologies for climate engineering, tend to rely on mathematical, and physical science-based interpretations and calculations, but this perspective can obscure if not completely erase complex social relations of neoliberalism that are, effectively, at the roots of the changing climate (Liverman, 2009). What is more, the physical science-dominated view that is central to climate engineering proposals is uninformed by a rich history of social science and humanities work on climate and climate change (Hulme, 2009). Cultural and historical studies focus on place-based experiences and interpretations of climate (Strauss and Orlove, 2003; Daniels and Endfield, 2009; Carey, 2012). Other work has emphasized the problematic nature of the global scale focus on climate change as neglecting other scales of lived, human experience (Fogel, 2004). Similarly, climate engineering, as discussed in the WGI report of the IPCC AR5, considers the environment in isolation from human systems even though these technologies are expected to generate unprecedented manipulations of environmental systems. Risk is interpreted along the lines of physical variables for which data are available or generalized in vague abstractions.

The reports from WGII and WGIII connect climate engineering proposals to human systems thereby expanding the scope of what "the" environment is. When environmental features and processes are considered in relation to human systems, the meaning of the environment shifts from being distinct from humans toward being a life support system 
intertwined with human activity. These two reports acknowledge that any advantages or disadvantages of climate engineering deployments would be distributed unevenly within and across generations, and already vulnerable groups of people would likely be negatively impacted by alterations in precipitation patterns and agricultural productivity. These general, nonspecific speculations are a nod to ways in which climate engineering technologies, as manipulations of environmental features, would likely interact with social and economic systems. Here, environment-human interactions are recognized although not specified with much detail. The Working Group reports of the AR5 also recognize that climate engineering technologies and deployments could generate political tensions over who gets to make decisions about deployments or over adverse impacts associated with these deployments. As a potential risk, political tension is difficult to measure in futuristic terms. The discussions in these reports consider security implicitly. There appears to be an understanding that these technological deployments aimed at securing particular global or hemispheric atmospheric measures carry implications for new or worsened forms of human and ecosystem insecurity. Without specific measures, calculations, or knowledge of those forms of insecurity, however, these issues appear to be considered a less palpable or less operational form of risk.

Assessing environmental features in a scientifically measurable, mechanistic way as these climate engineering discussions do, goes beyond representing environmental features to composing a narrative about what is worth our attention (Goeminne, 2010). Climate engineering proposals, as portrayed and summarized by the IPCC AR5, compose the environment as a set of interacting parts that is observable, measurable, and manipulatable. The report from WGI holds climate engineering as mostly separate and distinct from human systems; the reports from WGII and WGIII consider how deployments of various CDR and SRM technologies could interact with human systems in a broad sense, but the impacts and risks are repeatedly categorized as largely unknown.

Missing from these discussions of climate engineering throughout the AR5 is a recognition that the changing climateand humans' role and relationship to it-is in a state of flux. The AR5 includes graphics and data that indicate how measurable environmental features are changing, but the conversations on climate engineering pay little to no attention to how human systems are changing or would have to change in the context of large scale deployments of these proposed technologies. What do these technologies aim to stabilize or secure? Cudworth and Hobden (2011) have observed that environmental security framings tend to focus on a dualism between humans and "the" environment. A shortcoming of this conceptualization is that it tends to overlook important disparities between different groups of human and across different forms of insecurity. Not only are there multiple, non-human "environments" undergoing unprecedented, human-induced changes, there are also multiple intersectionalities of human populations and vulnerabilities, fraught with unequal power relations, that contribute to different experiences of insecurity. McDonald (2013) has considered how different interpretations of security-national, human, ecological, etc.-offer "different conceptions of who is in need of being secured, from what threat, by what actors, and through what means" (p. 49). He observes that the predominant discourses of national and international security may have the most traction among decision makers, but the policies and practices those interpretations would implement are the least likely to move beyond the status quo toward an adequate response to the changing relationship between humans and our life support system. Indeed, there are governance and jurisdictional questions about climate engineering (Boyd, 2009). These questions go beyond traditional, interstate relations and include scientific organizations, corporations, and other groups and organizations that are promoting or resisting the deployment of these proposed technologies, so familiar practices of state sovereignty and state-level geopolitics do not provide sufficient guidance for these decisions (Dalby, 2015). Familiar geopolitical thinking centered on territorial states with fixed boundaries will be of limited usefulness in the current context where humanenvironment interactions are already in flux (Dalby, 2020). Security and its practices of drawing boundaries between that which is important or protected and everything else becomes less clear as an objective in the context of a changing global climate. It becomes less clear what kinds of boundaries-territorial, chemical, geophysical-are to be established where, by whom and how. In the broader context of the Anthropocene, Fagan (2017) has suggested that we might think in terms of opportunity: "to rethink politics as something other than security politics, as a politics of vulnerability" (p. 311). The treatment of climate engineering proposals as largely a concern for manipulating physical features of the environment does not allow for these kinds of forward-looking, integrative perspectives.

In the context of the IPCC AR5 coverage of climate engineering, notions of security and risk, although rooted in an understanding of human survivability on the planet, are translated into physical measures of atmospheric gasses and planetary temperature. These measures are not then retranslated into locally operational understandings of security (or vulnerability). Security and risk appear to be generalized at the planetary level with an assumption that physical measures will meaningfully translate into societal and political measures. Rooted in physical sciences as much of climate engineering work is, there is insufficient language and expertise to generate understanding or practices of security-or even risk aversionthat might contribute to a fuller picture of implications of climate engineering.

\section{Selective Focus on Humans' Role and Agency}

The second observation of environmental geopolitics is that political claims about environmental features are often selective in their portrayal of how human systems interact with the feature in question. This observation encourages questions about how a particular environmental feature is presented as important, useful, or threatening to human activity. It encourages critical assessment about how and through what means the environmental feature is understood and assessed in relation 
to human interests even though that relationship may not be addressed explicitly. As noted at the end of the previous section, the exclusion of certain aspects of climate engineering, such as implications for political and social systems, serves to reinforce the notion that current societal systems will be able to accommodate futures generated by climate engineering proposals. This section considers how the IPCC AR5 coverage of climate engineering connects or relates those technologies, selectively, to human and societal systems.

A table in Chapter 6 of the Working Group I report boasts the lengthy title, "Table 6.15 Characteristics of some CDR methods from peer-reviewed literature. Note that a variety of economic, environmental, and other constraints could also limit their implementation and net potential" (p. 549). This title acknowledges that carbon dioxide removal technologies interact with or impact other environmental and human systems in unknown or unstudied ways. Granted, the focus of WGI is predominantly physical rather than social science, so it would be unreasonable, perhaps, to expect much deep analysis of humanenvironmental interactions. From another view, however, the changing climate emerges from human activity, so it might also seem just as unreasonable not to consider human-environmental interactions as central to the discussion.

Later chapters of the Working Group II report, however, shift attention to societal implications of climate engineering. A discussion in Ch. 12 recognizes that geoengineering "remains an unproven strategy to address climate change" and acknowledges the "high levels of uncertainty and high likelihood of differential geographic impacts" (p. 776) of these approaches. The chapter raises concerns about the potential for increased interstate tension and conflict. This chapter cites some social science literature to support concerns that geoengineering techniques could be used for hostile, military purposes (p. 777).

In the WGII report, Ch. 19, titled, "Emergent Risks and Key Vulnerabilities," considers "widespread risks to society and ecosystems" that geoengineering would likely pose (p. 1043), and it acknowledges that the "potential impacts of geoengineering strategies are considered a newly assessed or emergent risk" (p. 1062). CDR is considered lower risk than SRM if the mechanisms for storing $\mathrm{CO}_{2}$ are safe and avoid "unintended consequences for land use, the food system, and biodiversity" (p. 1065). SRM's potential impacts on society and ecosystems, however, are likely to be widespread and larger in magnitude. The chapter notes that, "Current knowledge on SRM is limited and our confidence in the conclusions in this section is low" (p. 1065). Without global agreements about how and how much stratospheric SRM to deploy, this chapter suggests there could be potential for international conflict related to SRM. This technology would be inexpensive to deploy relative to mitigation or adaptation (Barrett, 2008; Robock et al., 2009; McClellan et al., 2012), and it is possible that small states or even non-state actors could attempt to deploy SRM for their own benefit, which could also contribute to political tension absent robust governance (Victor, 2008; Lloyd and Oppenheimer, 2014). This chapter of the AR5 considers the question, "Does geoengineering present a moral hazard?" (Lin, 2013) in that these technologies might provide a false sense of solution to warming and a distraction from mitigation efforts.
Chapter 20 of the WG II report is titled, "ClimateResilient Pathways: Adaptation, Mitigation, and Sustainable Development" and considers how geoengineering could interact with human systems, broadly, such as ongoing efforts at mitigation and in sustainable development. This chapter recognizes a "very serious need" (p. 1125) for research into costs, benefits, risks, and multiple impacts of geoengineering technologies. Additionally, it will be important to develop a clearer understanding of connections between decision making regarding geoengineering and the distribution of equity in the likely impacts.

The Working Group III report, "Mitigation of Climate Change" (IPCC, 2014c), also includes discussion about climate engineering and offers a slightly different perspective. Within this report, Chapter 3, "Social, Economic, and Ethical Concepts and Methods," offers a brief, one-page discussion of moral considerations of SRM and CDR methods generally. Arguments in favor of climate engineering consider how launching these technologies might be a better option than unmitigated climate change, could possibly be more cost effective than other mitigation or adaptation strategies, and may be necessary in addition to other strategies in order to stabilize the climate. (p. 219). Arguments against climate engineering point out that large scale deployments of SRM or CDR carry substantial and "unresolvable" uncertainties (p. 219) and unintended side effects that are likely to be irreversible. These technologies could potentially worsen the climate situation and counteract any mitigation efforts.

As a previous section of this paper discusses, the IPCC and its Assessment Reports primarily emphasize the technical aspects of climate science and fail to incorporate the work and perspective of authors from the social sciences in a meaningful way (Bjurström and Polk, 2011). The work of the IPCC, and the larger field of Global Environmental Change science from which it emerges, has been scrutinized as being too limited in focus and in operability. As a field, Global Environmental Change science has been called upon, "to renew its social contract with society by moving beyond a focus on biophysical limits and toward solution-oriented research" and to "reorient itself from a focus on biophysically oriented, global-scale analysis of humanity's negative impact on the Earth system to consider the needs of decision makers from household to global scales" (DeFries et al., 2012 p. 603). Writing from the view of Environmental Social Science and Humanities, Castree et al. (2014) take this idea further to reject the common approach to "human dimensions" which often takes the form of studying both the biophysical and human worlds with similar concepts. They observe that, "by refusing to explore the full range of values, means and ends that might guide human responses to Global Environmental Change, researchers may implicitly endorse the societal status quo by neglecting to question it fundamentally" (p. 764). It is worthwhile to consider how these arguments apply to the IPCC's portrayal of climate engineering proposals and to ask questions such as: Who has the ultimate "say" in climate engineering proposals and implementation policy? Which groups of people stand to benefit from climate engineering implementation? Which groups of people would (still) be vulnerable if these proposed technologies 
are deployed? Answering these questions will serve to humanize the technicalities of climate engineering and un-obscure power dynamics or bias that are far too often hidden by rhetoric of "scientific objectivity" or "recommendations for policymakers."

Consider the example of SRM technologies as discussed in the IPCC AR5. Different SRM scenarios can be critiqued differently depending on the scale or nature of their implementation. For example, a "limited deployment scenario" with the intention of decreasing the current rate of warming by half, would require the delivery of 1.5 million tons of sulfur to the lower stratosphere, (Smith and Wagner, 2018, p. 5). Aside from these calculations about physical interactions, what would be the impacts of such a deployment on human systems? The discussion of SRM technologies in in Ch. 7 of the AR5 WGI report, as summarized in an earlier section, reflects what is understood about the physical science of these technologies, and the anticipated risks are also discussed in terms of the physical science of changes in rainfall patterns and ozone depletion. Other risks or implications for human systems such as agriculture are referred to in more sweeping and vague terms with reference to concerns for ethics and justice. There is no discussion about how global- or hemispheric climatic security in terms of atmospheric measures might intersect with security in terms of human wellbeing and justice.

It is clear that impacts on human systems are anticipated with these technological deployments, but they are not understood with any level of detail or confidence. The prioritization of what is more known about the physical science downplays questions about negative human impacts that are not addressed with any level of operability. Risk and security of climate engineering technologies, then, are reduced to variables of physical science without a balanced consideration of specific risks that these technologies pose to human systems. Additionally, security is also implicitly reduced to calculations of atmospheric composition rather than couched in terms that are meaningful to different groups of people and questions about how decisions around these technologies can or should be made.

Another important angle of human agency that is obscured in the IPCC AR5's coverage of SRM is how these technologies are being promoted. Szerszynski et al. (2013) have discussed how recent policy treatments of SRM technologies have not addressed the ways that these technologies, by the nature of how they would work, cannot operate within the liberal democratic political system and how they would be unmanageable within that system. Stephens and Surprise (2020) have considered the kinds of organizations and institutions that are funding and pursuing research on SRM technologies, and these bodies are not representative or democratic. In the pursuit of objective science that can be packaged and easily communicated to policymakers, the IPCC and other proponents of geoengineering fail to do the hard work of recognizing the many ways that such technological deployments and impacts could interact with societal systems.

This matters further given the tendency for discussions of geoengineering to slip into a securitization narrative. Scholars such as Lockley (2019) have raised warnings of the potential security risks of SRM as a geopolitical "flashpoint" for conflict (p. 103), arguing that the use of such technologies by a range of actors including states, philanthropic private citizens, and terrorist groups creates circumstances ripe for violent international conflict. Clark (2013) and others (Marzec, 2015) have cautioned against the securitization of climate change, arguing that climate engineering done from the perspective of an emergency security threat by military actors "is likely to override democratic procedure and undermine the nascent architectures of collective environmental governance" (Clark, 2013, p. 2827). Anticipatory language shapes how we discuss, understand, and create the future (Castree, 2020; see also Beck and Oomen, 2021), and the depoliticized language of the IPCC allows climate engineering technologies to be metaphorized as a potential security threat or tool to be used by military forces. IPCC reports tend to slip from scientific assessment to a focus on security threats, constricting the resulting conversation to one that is conducted through a securitized framework and that shuts down the possibility to consider other outcomes than militarized responses to climate impacts. IPCC analysis of climate change often warns that climate impacts have security implications, and reports have been explicitly cited in military reports defining climate change as a threat to national security. One significant and widely-cited example of this invocation of security implications of climate change is the 2007 report from the CNA, "National security and the accelerating risks of climate change" (CNA, 2007; see also CNA, 2014). This report is known as one of the first instances of U.S. military experts acknowledging climate change as a security threat and describing it as a "threat multiplier." The CNA report explicitly mentions the IPCC as foundational to its analysis, and it is cited throughout the report. Yet the way that security tends to be understood in these conversations is not particularly relevant to concerns about ethics and justice acknowledged throughout the IPCC AR5. One idea to move beyond familiar concepts of security and risk would be to think in terms of catastrophe. "More than disaster or risk, catastrophe brings out the political issues that surround the invocation of imaginaries of the future" (Aradau and Van Munster, 2011, p. 6). In part, the concept of catastrophe could "radically disrupt existing social structures" (p. 2), but how might the IPCC as an established, scientific organization, respond to that level of interruption?

\section{Selective Spatial Considerations}

The third observation of an environmental geopolitics analysis is that political claims about environmental features often focus on particular spatial scales that suit an underlying argument or agenda. This observation encourages thinking around how the environmental feature-and the human systems with which it is intertwined-is geographically complex and multi-faceted. That is, it invites questions about how this particular humanenvironment interaction connects different places, contributes to place-making, or serves the needs or interests of some groups of people or some places over others. A political claim about an environmental feature or process may focus on a particular spatial scale for a reason, but how does understanding of the claim or the environmental feature expand when other spatial scales and spatial connections are investigated?

The WGIII report offers some specific spatial considerations of proposed climate engineering technologies. Geographically, 
large scale deployments of SRM could significantly alter precipitation and temperature patterns to the detriment of already vulnerable groups of people. Large scale deployments of CDR could alter land use patterns and detract from agricultural productivity. Either of these deployments could contribute to geopolitical tensions over which state or group of states is able to make decisions about deployments and, effectively, control over climatic features. There is also discussion in this report about the implications of even doing research on climate engineering. Research on these technologies might be taken as an indication that efforts to decrease greenhouse gas emissions are not needed. There are also concerns that research on these technologies, including field-testing, could make their full scale deployment inevitable. The chapter does not offer a recommendation, either way, on climate engineering.

In the WGIII report, Chapter 6, "Assessing Transformation Pathways," acknowledges that methods proposed to remove $\mathrm{CO}_{2}$ from the atmosphere and storing it in land, geologic layers or in the ocean vary considerably in likely cost, in scalability, in risks they pose to humans and environmental systems, and in how much research has been done on the likely risks. The chapter offers the alternative term, "negative emissions technologies" (p. 485 ) as another way to think about CDR. Following a summary of what is known along these various dimensions of these technologies, the discussion ends by noting similar concerns about CDR raised in other areas of the IPCC AR5, namely, uncertainties associated with the risks, sustainability, and likely low impact on warming trends of these technologies and their potential to "exacerbate inter-generational impacts" (p. 486).

Chapter 6 of WGIII also considers a range of societal, economic, and political concerns that have been raised in other chapters such as regional disparities physical impacts, challenges of international agreement on how these technologies would be managed ["So far there are no legally binding international norms that explicitly address SRM, although certain general rules and principles of international law are applicable" (p. 488)], the risk of unilateral deployments by lone states or non-state actors, concerns over governance of these technologies as well as questions of distributive and procedural intra- and intergenerational justice. Chapter 13, "International Cooperation: Agreements and Instruments" of the WGIII report reiterates many of the same points as previous chapters and reports, and it considers a range of existing international agreements on other issues that may be useful in guiding geoengineering governance.

What is missing from the discussion is a sensitivity to the ways in which the spatial scales of these proposed technologies are mismatched to spatial scales of human activity beyond brief and general mention of, for instance, food supply systems. Also missing from the discussion is a sensitivity to place, place making, and how these technologies could significantly alter the spaces and places where human life and society unfold. As a discussion that originates in the limited language and spatialities of physical science, there is insufficient nuance and attention to extend an understanding to specific and explicit spaces of human activity. Much is lost in the spatial generalizations of physical systems, and the parts of the discussion that attempt to connect to societal systems fall back on clumsy tropes of interstate tensions. An environmental geopolitics perspective, however, can help to shed some light on why the IPCC AR5 coverage of climate engineering is so limited in its spatial understanding.

While IPCC AR5 aims to target global climate mitigation, the global contribution of knowledge for these reports is actually limited. The countries represented in the creation of this report are not globally representative and display a geographical divide. Most of the countries voiced in the IPCC are from North America and Europe, with a few South-East Asian countries and minimal representation from Latin America, Africa, and Central Asia. This trend was observed in the Third IPCC report, where there was minimal contribution from southern hemisphere countries that participated in the dialogue for climate mitigation at all (O'Neill et al., 2010). The absence or minimal role of these voices is a particular concern when uneven power dynamics are recognized, and these dynamics raise concerns related to climate engineering technologies.

Further, it is worth considering the extent to which the IPCC Working Groups are representative of a wide range of place-based, cultural, or disciplinary perspectives on climate. It has been argued that there are cultural and disciplinary biases in terms of participation makeup of these working groups which comprise the "hegemonic" institution of the IPCC (Corbera et al., 2016). That study, focused on Working Group III, arguably the Working Group with the greatest potential for multi-disciplinary contributions, found a dominance of US and UK based authors who contributed to the IPCC reports. The "social network" of contributing authors was analyzed to show with whom and with what institutions they collaborate. This information on the career paths of contributing authors also connected them to membership in dominant, Western organizations like the World Bank, the University of California at Berkeley, and the United Nations Framework Convention on Climate Change, among others. The study determined that authors and scholars in humanities disciplines remain marginally represented in IPCC reports compared to economists, engineers, and applied scientists. Moreover, even scholars who were originally from countries from the "South" tended to be trained in or employed by Northern institutions. The study concluded that the largely homogeneous makeup of the IPCC's authors- their national, institutional, and disciplinary backgrounds- is a likely contributing factor shaping the IPCC consensus reports. This homogeneous makeup of the IPCC's authors seems disproportionately to represent voices from "hard sciences" and fails to represent humanities and social sciences in a meaningful way. This lack of humanistic representation is evident in the lack of grounded, in-depth analysis of cultural and sociological understandings of climate engineering proposals.

Other scholars have drawn attention to problematic aspects of the uneven representation and agency of different groups of states in the conversation about climate engineering. As early as 1997, Litfin discussed how any effort to manage and monitor the climate system is only possible through a totalizing "global gaze" that erases societal differences while privileging the agenda of wealthier, technologically advanced actors (Litfin, 1997). Lövbrand et al. (2009) observe that, "Geoengineering involves 
direct control and manipulation of the Earth System and invokes notions of hierarchical steering and expert management" (p. 11). D'Souza (2015) considers implications of the North-South divide in the advancement and potential impacts of climate engineering:

What is striking for our purposes, however, is the fact that as voices in support of geo-engineering for a plan B strategy against climate change begin to acquire weight, several complicated ethical and political questions will perforce be thrown up. Notably, given that geo-engineering is meant to essentially operate at the global rather than national scale, there can be credible concern that bargaining models and negotiating frameworks might skew power in the hands of those paying for the technologies and those possessing the technical abilities to alter weather. On the other hand, how will unintended negative impacts be resolved if issues of justice and equity are to be met? And lastly, would the South or the developing world be at a policy disadvantage in deciding what priorities and outcomes geo-engineering must achieve? (p. 724)

The work behind the IPCC does not appear to be "global" in the sense that a range of different views, cultural perceptions, and place-based interpretations of human-environment interactions are included. The work is international in some ways, but there are disparities in terms of which countries, institutions, and disciplinary perspectives are represented in the work of the IPCC. The IPCC's portrayal of climate engineering, then, can be understood less as a "global" response to climate change and more of an area of work to which relatively few organizations and viewpoints are contributing.

The intended effects of these climate engineering technologies on atmospheric levels of greenhouse gases or reflectivity are understood through models and calculations of established measures. However, human impacts are considered only in vague terms in part because there is so much potential for different, place-specific impacts depending on economic, political, social, and environmental systems in different places. The human impact scale does not fit the technological deployment and impacts scale. For instance, SRM technology is thought to have the potential to "reduce the average temperature differences between day and night" (Boyd, 2009, p. 103), which is the exact desire of using the technology, only this potentially would "wreak havoc with local ecosystemic processes, including plant and animal populations, wind, and precipitation" (p. 103) as well as decreasing rainfall in ecosystems that desire it the most, like in Africa, and rely on heavy surpluses of water for a healthy system, like the Amazon (Michaelson, 2013). Indeed, the Working Group reports summarized in previous sections impart that climate engineering technologies would likely impact environmental and human systems in unknown or unstudied ways and with unanticipated consequences. According to the models and projections of physical scientists, there would likely be changes in regional rainfall patterns, land use patterns, and agricultural productivity. The report recognizes that any of these regional or localized changes will unfold within the social, political, and economic conditions of those places and could have implications for justice concerns. Negative impacts of climate engineering technologies appear to be unmeasurable in terms of particular metrics of impact, severity, and temporal longevity. In the AR5, analysis at the spatial scale of human experience is admittedly less refined than the "hard" science aspects of climate engineering technologies in part because work in the social sciences and the humanities is not the main area of expertise for the IPCC.

As discussed at different points in this paper, security has different meanings and implications. In the IPCC AR5, climate engineering technologies are aimed at altering global measures of security in terms of atmospheric $\mathrm{CO}_{2}$ and incoming solar radiation. Ironically, interest in these technologies seems motivated by a concern about risks that threaten the ability to continue to operate within our familiar systems of production and consumption. These technologies are discussed in terms of securing planetary systems, and it appears to be assumed that whatever is good for the planet is good for the systems operating on the planet. However, either because of how the technologies are conceived or perhaps because of the institutional and academic limits of the researchers proposing these technologies, the spatial scales of the many likely impacts of these proposed technologies are not made visible, measurable, or meaningful. The spatial scales of anticipated benefit are not necessarily inclusive. The influence inherent in these technologies would appear to be focused on perpetuating and reproducing the concentrated systems of power that have contributed significantly to the changing climate.

\section{CONCLUDING THOUGHTS}

An environmental geopolitics analysis is useful in identifying agendas or values embedded within a political claim about the environment. In this paper, we have considered how the IPCC AR5 portrays climate engineering. This discussion is a claim in the sense that the IPCC is recognized as a legitimate, international authority on the matter of climate change and possible responses to it. The fact that the IPCC includes consideration of climate engineering technologies at all is, in a sense, a claim or acknowledgment that these areas of research should be considered part of a comprehensive assessment of the current state of knowledge about climate change. This conversation is necessarily political. Even though the IPCC does not offer policy recommendations, as the preeminent scientific authority on climate change, it matters what the IPCC includes as legitimate science.

We have considered three aspects of the IPCC's AR5 portrayal of climate engineering: How is "the" environment understood, interpreted and valued in the discussions about climate engineering technologies? How are humans and human activity considered in the context of climate engineering, either explicitly or implicitly? Which spatial considerations and implications are considered in this conversation, and which others are overlooked? In exploring each of these questions, we focused on how ideas of security or risk were integrated into the conversation as a way to justify actions or inactions.

Climate engineering, as discussed in the different Working Group reports of the AR5, is cast as an issue of planetary 
management through models and calculations of physical science such as the chemical and heat-trapping capacity of the atmosphere, measures of reflectivity of the atmosphere, and calculations of potential impacts on other physical features such as long- and short-term planetary surface temperature changes, ocean acidification, the global water cycle, and so forth. Even within parameters of uncertainty, these physical relationships are discussed as being understood well enough to assert the potential of these technologies to generate some degree of change in the desired direction. The environment is understood as a collection of interacting parts that may be studied, modeled, and potentially managed. There is also the recognition that environmental features interact with human systems and that climate engineering technologies could have unintended implications for human-environment interactions such as agricultural productivity, land use, and tensions over resource use and access. The dominance of physical science interpretations, as opposed to place-based and human-scaled approaches of the humanities and social sciences, tends to separate physical, environmental features and systems from human activity. Although the conversation touches at several times on human-focused concerns such as ethics and justice concerns about climate engineering, these parts of the conversation are relatively stunted and lack a richer interpretation from disciplines well-suited to these considerations. These limitations stem from the relatively tight academic networks, predominance of Western research institutions and organizations, and entrained consensus-driven thinking that make up most of the IPCC's work. The mainstream understanding of climate change promoted by the IPCC prioritizes physical science as a way to interpret the world and is less curious or attentive to other ways of knowing. There is little criticism around "the illusory nature of hard numbers" (Bridge, 2010, p. 526).

To offer one, humanistic counter example, we can look to an Indigenous perspective:

\footnotetext{
...while we race around asking how we might change technology or tax structures, the change that might save us goes unspoken: what we need to change is ourselves. The danger is that we have been captured by a worldview that no longer serves our world, if it ever did...We need a change in heart, a change in ethics, away from an anthropocentric worldview that considers the Earth our exploitable property to a biocentric, life-centered worldview in which an ethic of respect and reciprocity can grow" (Kimmerer, 2014, p. 22)
}

In its 4th Assessment Report in 2007, the IPCC acknowledged Indigenous knowledge as an "invaluable basis for developing adaptation and natural resource management strategies in response to environmental and other forms of change" (Parry et al., 2007), and this idea could be usefully extended to climate engineering proposals. However, "traditional knowledge either appears in gray literature outside of peer-reviewed academic forums, or remains in oral form, thereby falling outside the scope of IPCC process" (Raygorodetsky, 2011). Scholars have considered ways in which Indigenous knowledge not only offers a "counterhegemonic discourse to the "global" Western construction of climate change" (Smith, 2007, p. 198), but could be usefully integrated-not assimilated-into discussions about climate engineering (Palmer, 2006; Mercer, 2021). Other research has considered what Indigenous consent in the climate engineering conversation might look like (Whyte, 2012).

So, although the global or hemispheric implications of how these technologies might alter measures of climate, there is much less work or understanding within the IPCC AR5 of the implications of these technologies on societal, economic, cultural, and political systems. Similarly, an understanding of climate engineering technologies seems to be the most clear at the global or even regional spatial scales and becomes murkier and vaguer at the scale of human experience. The overarching objective of deploying climate engineering technologies, nominally, is to stabilize particular features of the global climate so that human life may continue to be supported. Whether the proposal is to trap greenhouse gases away from the atmosphere or to reduce the amount of solar radiation that reaches earth's surface, these technologies are promoted as a means to render the climate secure and predictable. That argument may be relevant for the global or hemispheric scale, but those claims to security fail at other spatial scales. Anticipated risks inherent in these technologies are envisioned at multiple spatial scales but are not well understood. Familiar, state-level approaches to securing predictable circumstances within clear boundaries are not likely to be very useful in this context leaving many questions about how these proposed technologies and their impacts could be governed and managed in a way that takes justice and ethical concerns seriously.

What agenda becomes evident through this analysis? Climate engineering technologies and the ways in which they are portrayed and summarized in the IPCC AR5 would appear to allow or justify a delay in pursuing substantive mitigation actions. Mitigation in any meaningful sense would certainly involve difficult decisions about arrangements of consumption, wealth, and well-being. Despite the repeated skepticism about these technologies, they seem to offer a glimmer of potential. It is not important for them to offer a compelling way forward. It is only important that they offer a wedge of doubt that hard choices about mitigation are the only way forward (see Oreskes and Conway, 2010). These technological proposals, in all their complexity and urgency, would seem to invite the possibility of procrastination and to stabilize the current uneven geographies of entrenched power and injustice.

\section{DATA AVAILABILITY STATEMENT}

Data used in this article are publicly available on the IPCC website: https://www.ipcc.ch/report/ar5/syr/.

\section{AUTHOR CONTRIBUTIONS}

SO' $\mathrm{L}$ is the lead author of this work. $\mathrm{MH}, \mathrm{AN}$, and LS contributed significantly and equally to this work. SW and JP contributed to this work as last authors. All contributing authors approved the manuscript for publication. 


\section{ACKNOWLEDGMENTS}

The authors wish to thank the Geography and Atmospheric Science Department and the Environmental Studies Program at

\section{REFERENCES}

Amoore, L. (2014). Security and the incalculable. Secur. Dialog. 45, 423-439. doi: $10.1177 / 0967010614539719$

Aradau, C., and Van Munster, R. (2011). Politics of Catastrophe: Genealogies of the Unknown. New York, NY: Routledge.

Barnett, J. (2001). The Meaning of Environmental Security: Ecological Politics and Policy in the New Security Era. Winnipeg, MB: Zed Books.

Barrett, S. (2008). The incredible economics of geoengineering. Environ. Resource Econ. 39, 45-54. doi: 10.1007/s10640-007-9174-8

Baskin, J. (2019). Geoengineering, the anthropocene and the end of nature. London: Palgrave Macmillan.

Beck, S., and Mahony, M. (2018). The IPCC and the new map of science and politics. Wiley Interdisciplin. Rev. Clim. Change 9:e547. doi: 10.1002/wcc.547

Beck, S., and Oomen, J. (2021). Imagining the corridor of climate mitigationWhat is at stake in IPCC's politics of anticipation? Environ. Sci. Policy 123, 169-178. doi: 10.1016/j.envsci.2021.05.011

Beck, U. (1992). Risk Society: Towards a New Modernity. Transl. by Mark Ritter. London: Sage Publications.

Beck, U. (2009). World at Risk. Translated by Ciaran Cronin. Cambridge, MA: Cambridge University Press.

Bijker, W. E. (2001). "Understanding technological culture through a constructivist view of science, technology, and society," in Visions of STS: Counterpoints in Science, Technology, and Society Studies, ed. S.H. Cutcliffe and C. Mitcham (Albany, NY: State University of New York Press), 19-34.

Bjurström, A., and Polk, M. (2011). Physical and economic bias in climate change research: a scientometric study of IPCC Third Assessment Report. Clim. Change 108, 1-22. doi: 10.1007/s10584-011-0018-8

Blue, B., and Tadaki, M. (2019). "Getting the Measure of Nature: the inconspicuous geopolitics of environmental measurement," in A Research Agenda for Environmental Geopolitics, ed. S. O'Lear (Cheltenham: Edward Elgar Publishers).

Boyd, P. W. (2009). Geopolitics of Geoengineering. Nat. Geosci. 2:812. doi: $10.1038 /$ ngeo710

Bridge, G. (2010). Geographies of peak oil: The other carbon problem. Geoforum 41, 523-530. doi: 10.1016/j.geoforum.2010.06.002

Buzan, B., Waever, O., and de Wilde, J. (1998). Security: A New Framework for Analysis. London: Lynne Rienner.

Carey, M. (2012). Climate and history: a critical review of historical climatology and climate change historiography. Wiley Interdisciplin. Rev. Clim. Change 3, 233-249. doi: 10.1002/wcc.171

Castree, N. (2003). "The Geopolitics of nature," in A Companion to Political Geography, ed. J. Agnew, K. Mitchell, and G. Toal (Malden, MA: Blackwell Publishing), 423-439.

Castree, N. (2020). The discourse and reality of carbon dioxide removal: toward the responsible use of metaphors in post-normal times. Front. Clim. 2:614014. doi: $10.3389 /$ fclim.2020.614014

Castree, N., Adams, W. M., Barry, J., Brockington, D., Büscher, B., Corbera E., Demeritt, D., Duffy, R., Felt, U., Neves, K., Newell, P., Pellizzoni, L., Rigby, K., Robbins, P., Robin, L., Rose, D. B., Ross, A., Schlosberg, D., Sörlin, S., West, P., Whitehead, M., and Wynne B. (2014). Changing the intellectual climate. Nat. Clim. Change 4, 763-768. doi: 10.1038/nclimate2339

Clark, N. (2013). Geoengineering and geologic politics. Environ. Plann. 45, 2825-2832. doi: 10.1068/a45646

CNA (2014). Military Advisory Board National Security and the Accelerating Risks of Climate Change. Alexandria, VA: CNA Corporation. Available onlie at www.cna.org/reports/accelerating-risks (accessed May 28, 2021).

CNA. (2007). National Security and the Threat of Climate Change. Report from a panel of retired senior US military officers. Alexandria, VA: CNA Corporation. Available online at: http://www.cna.org/reports/climate (accessed May 6, 2021). the University of Kansas for making this research collaboration possible. Two reviewers offered thoughtful and constructive suggestions that strengthened the paper, and we are grateful for their contributions.
Cohen, S., Demeritt, D., Robinson, J., Rothman D. (1998). Climate change and sustainable development: towards dialogue. Global Environ. Change 8, 341-371. doi: 10.1016/S0959-3780(98)00017-X

Corbera, E., Calvet-Mir, L., Hughes, H., et al. (2016). Patterns of authorship in the IPCC Working Group III Report. Nat. Clim. Change 6, 94-99. doi: $10.1038 /$ nclimate2782

Cudworth, E., and Hobden, S. (2011). Beyond environmental security: complex systems, multiple inequalities and environmental risks. Environ. Politic. 20, 42-59. doi: 10.1080/09644016.2011.538165

Dalby, S. (1991). Critical geopolitics: discourse, difference, and dissent. Environ. Plann. Soc. Space 9, 261-283. doi: 10.1068/d090261

Dalby, S. (2009). Security and Environmental Change. Malden, MA: Polity Press.

Dalby, S. (2015). Geoengineering: the next era of geopolitics? Geograp. Compass 9, 190-201. doi: 10.1111/gec3.12195

Dalby, S. (2020). Anthropocene Geopolitics: Globalization, Security, Sustainability. Ottawa ON: University of Ottawa Press.

Daniels, S., and Endfield, G. H. (2009). Narratives of climate change: introduction. J. Hist. Geogr. 35, 215-222. doi: 10.1016/j.jhg.2008.09.005

DeFries, R. S., Ellis, E. C., Chapin III, F. S., Matson, P. A., Turner II, B. L., Agrawal, A., Crutzen, P. J., Field, C., Gleick, P., Kareiva, P. M., Lambin, E., Liverman, D., Ostrom, E., Sanchez, P. A., and Syvitski J., (2012). Planetary opportunities: a social contract for global change science to contribute to a sustainable future. Bioscience 62, 603-606. doi: 10.1525/bio.2012.62.6.11

Demeritt, D. (2009). From externality to inputs and interference: framing environmental research in geography. Trans. Instit. Br. Geograph. 34, 3-11. doi: 10.1111/j.1475-5661.2008.00333.x

D'Souza, R. (2015). Nations without borders: climate security and the South in the Epoch of the anthropocene. Strateg. Anal. 39, 720-728. doi: 10.1080/09700161.2015.1090678

Edwards, P. N. (2010). A Vast Machine: Computer Models, Climate Data, and the Politics of Global Warming. Cambridge, MA: MIT Press.

Fagan, M. (2017). Security in the anthropocene: Environment, ecology, escape. Euro. J. Int. Relat. 23, 292-314. doi: 10.1177/135406611663 9738

Fischetti, M. (2021). We are Living in a Climate Emergency, and we're Going to say so. Scientific American. Available online at: https://www.scientificamerican. com/article/we-are-living-in-a-climate-emergency-and-were-going-to-sayso/ (accessed May 3, 2021)

Fogel, C. (2004). "The local, the global, and the Kyoto Protocol," in Earthly Politics: Local and Global in Environmental Governance, ed. S. Jasanoff and M.L Martello (Cambridge, MA: Cambridge University Press), 103-125.

Gemenne, F. (2015). "The Anthropocene and Its Victims," in The Anthropocene and the Global Environmental Crisis: Rethinking Modernity in a New Epoch, ed. C. Hamilton, C. Bonneuil, and F. Gemenne (New York, NY: Routledge), 168-174.

Gieryn, T. F. (1983). Boundary-work and the demarcation of science from nonscience: Strains and interests in professional ideologies of scientists. Am. Sociol. Rev. 48, 781-795. doi: 10.2307/2095325

Glover, L. (2016). "Postmodern Interpretations," in Reframing Climate Change: Constructing Ecological Geopolitics, ed. S. O'Lear and S. Dalby (New York, NY: Routledge) 14-30.

Goeminne, G. (2010). Climate policy is dead, long live climate politics. Ethics Place Environ. 13, 207-214. doi: 10.1080/13668791003778867

Goes, M., Tuana, N., and Keller, K. (2011). The economics (or lack thereof) of aerosol geoengineering. Clim. Change 109, 719-744. doi: 10.1007/s10584-010-9961-z

Hamilton, C. (2014). Geoengineering and the politics of science. Bull. Atom. Scien. 70, 17-26. doi: 10.1177/0096340214531173

Hamilton, C., Bonneuil, C., and Gemenne, F. (2015). "Thinking the Anthropocene," in The Anthropocene and the Global Environmental Crisis: 
Rethinking Modernity in a New Epoch, ed C. Hamilton, C. Bonneuil, and F. Gemenne (New York, NY: Routledge), 1-14.

Herrando-Pérez, S., Bradshaw, C. J. A., Lewandowsky, S., and Vieites D. R. (2019). "Statistical language backs conservatism in climate-change assessments. Bioscience 69, 209-219. doi: 10.1093/biosci/biz004

Hiramatsu, A., Mimura, N., and Sumi, A. (2008). A mapping of global warming research based on IPCC AR4. Sustain. Sci. 3, 201-213. doi: 10.1007/s11625-008-0058-9

Hulme, M. (2009). Why we Disagree About Climate Change. Cambridge, UK: Cambridge University Press.

Hulme, M., and Mahony, M. (2010). Climate change: What do we know about the IPCC? Progr. Physic. Geograph. 34, 705-718. doi: 10.1177/0309133310373719

Huysmans, J. (1998). Security! What do you mean?: From concept to thick signifier. Euro. J. Int. Relat. 2, 226-255. doi: 10.1177/13540661980040 02004

IPCC (2013). "Climate change 2013: the physical science basis," in Contribution of Working Group I to the Fifth Assessment Report of the Intergovernmental Panel on Climate Change, eds T. F. Stocker, D. Qin, G. K. Plattner, M. Tignor, S.K. Allen, J. Boschung, A. Nauels, Y. Xia, V. Bex and P.M. Midgley (Cambridge : Cambridge University Press), 1535.

IPCC (2014a). "Climate change 2014: impacts, adaptation, and vulnerability. part a: global and sectoral aspects," in Contribution of Working Group II to the Fifth Assessment Report of the Intergovernmental Panel on Climate Change, eds C. B. Field, V.R. Barros, D.J. Dokken, K.J. Mach, M.D. Mastrandrea, T.E. Bilir, M. Chatterjee, K.L. Ebi, Y.O. Estrada, R.C. Genova, B. Girma, E.S. Kissel, A.N. Levy, S. MacCracken, P.R. Mastrandrea, and L.L.White (Cambridge: Cambridge University Press), 1132

IPCC (2014b). "Climate change 2014: impacts, adaptation, and vulnerability. part B: regional aspects," in Contribution of Working Group II to the Fifth Assessment Report of the Intergovernmental Panel on Climate Change, eds V. R. Barros, C.B. Field, D.J. Dokken, M.D. Mastrandrea, K.J. Mach, T.E. Bilir, M. Chatterjee, K.L. Ebi, Y.O. Estrada, R.C. Genova, B. Girma, E.S. Kissel, A.N. Levy, S. MacCracken, P.R. Mastrandrea, and L.L.White (Cambridge: Cambridge University Press), 688.

IPCC (2014c). "Climate change 2014: mitigation of climate change," in Contribution of Working Group III to the Fifth Assessment Report of the Intergovernmental Panel on Climate Chang, eds O. Edenhofer, R. Pichs-Madruga, Y. Sokona, E. Farahani, S. Kadner, K. Seyboth, A. Adler, I. Baum, S. Brunner, P. Eickemeier, B. Kriemann, J. Savolainen, S. Schlömer, C. von Stechow, T. Zwickel and J.C. Minx (Cambridge: Cambridge University Press), 151.

Jasanoff, S. (1996). Beyond epistemology: relativism and engagement in the politics of science. Soc. Stud. Sci. 26, 393-418. doi: 10.1177/03063129602600 2008

Kimmerer, R. W. (2014). Returning the gift. Minding Nat. 7, 18-24. Available online at: https://www.turtlelodge.org/wp-content/uploads/2017/08/ Kimmerer-Returning-the-Gift.pdf

Lasswell, H. D. (1937). Politics: Who gets what, when, how. Auckland: Pickle Partners Publishing.

Law, J. (2004). After Method: Mess in Social Science Research. New York, NY: Routledge.

Lemos, M. C., Klenk, N., Kirchhoff, C. J., Morrison, T., Bremer, S., Fischer, A. P., Soares, M. B., Torres, R. R., and Olwoch, J. M. (2020). grand challenges for climate risk management. Front. Clim. 2:605206. doi: 10.3389/fclim.2020.60 5206

Lin, A. (2013) Does geoengineering present a moral hazard? Ecology Law Quarterly. 40, 673-712. Available online at: https://escholarship.org/content/ qt7th0d0pd/qt7th0d0pd.pdf

Litfin, K. (1997). The gendered eye in the sky: a feminist perspective on Earth observation satellites. Front. J. Women Stud. 18, 26-47. doi: 10.2307/3346964

Liverman, D. M. (2009). Conventions of climate change: constructions of danger and the dispossession of the atmosphere. J. Historic. Geograph. 35, 279-296. doi: 10.1016/j.jhg.2008.08.008

Lloyd, E. A. (2012). The role of 'complex' empiricism in the debates about satellite data and climate models. Studies in History and Philosophy of Science Part A 43, 390-401. doi: 10.1016/j.shpsa.2012.02.001

Lloyd, I. D., and Oppenheimer, M. (2014). On the Design of an international governance framework for geoengineering. Global Environ. Politic. 14, 45-63. doi: 10.1162/GLEP_a_00228
Lockley, A. (2019). Security of solar radiation management geoengineering. Front. Eng. Manage. 6, 102-116. doi: 10.1007/s42524-019-0008-5

Lövbrand, E., Stripple, J., and Wiman, B. (2009). Earth System governmentality: reflections on science in the Anthropocene. Glob. Environ. Change 19, 7-13. doi: 10.1016/j.gloenvcha.2008.10.002

Malone, E. L., and Rayner, S. (2001). Role of the research standpoint in integrating global-scale and local-scale research. Clim. Res. 19, 173-178. doi: 10.3354/cr019173

Markusson, N., Balta-Ozkan, N., Chilvers, J., Healey, P., Reiner, D., and McLaren, D. (2020). Social Science Sequestered. Front. Clim. 2:2. doi: 10.3389/fclim.2020.00002

Marzec, R. P. (2015). Militarizing the Environment: Climate Change and the Security State. Minneapolis, MN: University of Minnesota Press.

McClellan, J., Keith, D. W., and Apt, J. (2012). Cost analysis of stratospheric albedo modification delivery systems. Environ. Res. Lett. 7:034019. doi: $10.1088 / 1748-9326 / 7 / 3 / 034019$

McDonald, M. (2013). Discourses of climate security. Politic. Geograph. 33, 42-51. doi: 10.1016/j.polgeo.2013.01.002

Mercer, H. (2021). Colonialism's Climatic Legacies. Available online at: https:// blog.history.ac.uk/2021/03/colonialisms-climatic-legacies/ (accessed April 01, 2021).

Michaelson, J. (2013). "Geoengineering and Climate Management: From marginality to inevitability," in Climate Change Geoengineering: Philosophical Perspectives, Legal Issues, and Governance Frameworks, eds C. Wil, G. Burns, and L. Andrew Strauss (New York, NY: Cambridge University Press), 81-114.

Mol, A. (2002). The Body Multiple: Ontology in Medical Practice. Durham: Duke University Press.

O' Tuathail, G., and Agnew, J. (1992). Geopolitics and discourse: practical geopolitical reasoning in American foreign policy. Polit. Geogr. 11, 190-204. doi: 10.1016/0962-6298(92) $90048-\mathrm{X}$

O'Lear, S. (2016). "Geopolitics and Climate Science: The case of the missing embodied carbon," in Reframing Climate Change: Constructing Ecological Geopolitics, ed. S. O'Lear and S. Dalby (New York, NY: Routledge), 100-115.

O'Lear, S. (2018). Environmental Geopolitics. Boulder: Rowman and Littlefield.

O'Lear, S. (2019). A Research Agenda for Environmental Geopolitics. Cheltenham: Edward Elgar Publishers.

O'Lear, S. (2020). "Environmental Geopolitics," in International Encyclopedia of Human Geography, 2nd edition, ed. A. Kobayashi (Cambridge, MA: Elsevier Ltd), 193-200.

O'Lear, S., and Dalby, S. (2016). "Reframing the climate change discussion," in Reframing Climate Change: Constructing Ecological Geopolitics, ed. S. O'Lear and S. Dalby (New York, NY: Routledge), 1-13.

O'Neill, S. J., Hulme, M., and Turnpenny, J., Screen J. A. (2010). Disciplines, geography, and gender in the framing of climate change. Bull. Am. Meteorol. Soc. 91, 997-1002. doi: 10.1175/2010BAMS2973.1

Oreskes, N., and Conway, E. M. (2010). Defeating the merchants of doubt. Nature 465, 686-687. doi: 10.1038/465686a

Palmer, L. (2006). 'Nature', place and the recognition of indigenous polities. Austr. Geograph. 37, 33-43. doi: 10.1080/00049180500511954

Parikh, J. K. (1992). IPCC strategies unfair to the South. Nature 360, 507-508, doi: $10.1038 / 360507 \mathrm{a} 0$

Parker, A., and Geden, O. (2016). No fudging on geoengineering. Nat. Geosci. 9, 859-860. doi: 10.1038/ngeo2851

Parry, M.L., Canziani, O. F., Palutikof, J. P., van der Linden, P. J., and Hanson, C. E. (2007). Contribution of Working Group II to the Fourth Assessment Report of the Intergovernmental Panel on Climate Change, (New York, NY: Cambridge University Press), Available online at: https://archive.ipcc.ch/publications and_data/ar4/wg2/en/xccsc4-2-3.html (accessed May 31, 2021).

Pearce, W., Mahony, M., and Raman, S. (2018). Science advice for global challenges: learning from trade-offs in the IPCC. Environ. Sci. Policy 80, 125-131. doi: 10.1016/j.envsci.2017.11.017

Peoples, C., and Vaughan-Williams, N. (2015). Critical Security Studies: An introduction. (London: Routledge)

Petersen, A. C. (2018). "The emergence of the geoengineering debate within the IPCC," in Geoengineering Our Climate? Ethics, Politics, and Governance, eds. J. J. Blackstock and S. Low (London: Routledge), 121-124.

Raygorodetsky, G. (2011). Why Traditional Knowledge Holds the Key to Climate Change. United Nations University, Available online at: https://unu.edu/ 
publications/articles/why-traditional-knowledge-holds-the-key-to-climatechange.html (accessed May 28, 2018)|.

Redclift, M. (1992). Sustainable development and global environmental change: implications of a changing agenda. Global Environ.Change 21, 32-42. doi: 10.1016/0959-3780(92)90034-5

Reynolds, J. L. (2021). Is solar geoengineering ungovernable? a critical assessment of governance challenges identified by the intergovernmental panel on climate change. Wiley Interdisciplin. Rev. Clim. Change 12:e690. doi: 10.1002/wcc.690

Robock, A., Marquardt, A., Kravitz, B., and Stenchikov, G. (2009). Benefits, risks, and costs of stratospheric geoengineering. Geophys. Res. Lett. 36:209. doi: 10.1029/2009GL039209

Shackley, S. (1997). The intergovernmental panel on climate change: consensual knowledge and global politics. Global Environ. Change 7, 77-79. doi: 10.1016/S0959-3780(96)00035-0

Shaw, A. (2005). "Policy relevant scientific information: the co-production of objectivity and relevance in the IPCC," in UC Berkeley Breslauer Symposium. Available online at: https://escholarship.org/uc/item/0d81p739 (accessed May 31, 2021).

Shepherd, J. G. (2009). Geoengineering the climate: science, governance and uncertainty. London: The Royal Society.

Shepherd, J. G. (2012). Geoengineering the climate: an overview and update. Philo. Trans. Royal Soc. A: Math. Phys. Eng. Sci. 370, 4166-4175. doi: $10.1098 /$ rsta.2012.0186

Slovic, P. (2016). Understanding Perceived Risk: 1978-2015. Environ. Sci. Policy Sustain. Develop. 58, 25-29. doi: 10.1080/00139157.2016.1112169

Smith, H. A. (2007). "Disrupting the global discourse of climate change: the case of Indigenous voices," in The Social Construction of Climate Change: Power, knowledge, norms, discourses, ed M. E. Pettenger (Burlington, VT: Ashgate), 197-215.

Smith, W., and Wagner, G. (2018). Stratospheric aerosol injection tactics and costs in the first 15 years of deployment. Environ. Res. Lett. 13:124001, doi: 10.1088/1748-9326/aae98d

Sovacool,. B. K. (2021). Reckless or righteous? reviewing the sociotechnical benefits and risks of climate change geoengineering. Energy Strat. Rev. 35:100656. doi: 10.1016/j.esr.2021.100656

Stephens, J., and Surprise, K. (2020). The hidden injustices of advancing solar geoengineering research. Glob. Sustain. 3, 1-6. doi: 10.1017/sus.2019.28

Strauss, S., and Orlove, B. S. (2003). Weather, Climate, Culture. New York, NY: Berg.

Surprise, K. (2020). Geopolitical ecology of solar geoengineering: from a 'logic of multilateralism' to logics of militarization. J. Politic. Ecol. 27, 213-235. doi: 10.2458/v27i1.23583

Szerszynski, B., Kearnes, M., Macnaghten, P., Owen, R., and Stilgoe, J. (2013). Why solar radiation management geoengineering and democracy won't mix. Environ. Plann. A 45, 2809-2816. doi: 10.1068/a45649

Van Fraassen, B. C. (2008). Scientific Representation: Paradoxes of Perspective. Oxford, UK: Clarendon Press.
Vaughan, N., Timothy, E., and Lenton. M. (2011). A review of climate geoengineering proposals. Clim. Change 109, 745-790. doi: 10.1007/s10584-011-0027-7

Victor, D. G. (2008). On the regulation of geoengineering. Oxf. Rev. Econ. Policy 24, 322-336. doi: 10.1093/oxrep/grn018

Victor, D. G., Gerlagh, R., and Baiocchi, G. (2014). Getting serious about categorizing countries. Science 345, 34-36. doi: 10.1126/science.1255302

Von Storch, H., Bunde, A., and Stehr, N., (2011). “The physical sciences and climate politics," in The Oxford Handbook of Climate Change and Society, eds. J.S. Dryzek, R.B. Norgaard, and D. Schlosberg (New York, NY: Oxford University Press) 113-128.

Walker, R. B. J. (1987). "The concept of security and International Relations theory," Working Paper No. 3, Series, First Annual Conference on Discourse, Peace, Security and International Society. Ballyvaughn, Ireland ed by J. M. Skelly.

Whyte, K. (2012). "Indigenous peoples, solar radiation management, and consent," in Engineering the Climate: The Ethics of Solar Radiation Management, (Washington, DC: Lexington Books), Available online at: https://ssrn.com/ abstract=2003187 (accessed May 28, 2021).

Wiertz, T. (2016). "Technology and politics in the Anthropocene: visions of 'solar radiation management,"' in Reframing Climate Change: Constructing Ecological Geopolitics, ed. S. O'Lear and S. Dalby (New York, NY: Routledge), 116-131.

Yearley, S. (2009). Sociology and climate change after Kyoto: what roles for social science in understanding climate change? Curr. Sociol. 57.3, 389-405. doi: $10.1177 / 0011392108101589$

Yusoff, K. (2013). The geoengine: geoengineering and the geopolitics of planetary modification. Environ. Plann. A: Econ. Space. 45, 2799-2808. doi: $10.1068 / \mathrm{a} 45645$

Conflict of Interest: The authors declare that the research was conducted in the absence of any commercial or financial relationships that could be construed as a potential conflict of interest.

Publisher's Note: All claims expressed in this article are solely those of the authors and do not necessarily represent those of their affiliated organizations, or those of the publisher, the editors and the reviewers. Any product that may be evaluated in this article, or claim that may be made by its manufacturer, is not guaranteed or endorsed by the publisher.

Copyright (c) 2021 O'Lear, Hane, Neal, Stallings, Wadood and Park. This is an open-access article distributed under the terms of the Creative Commons Attribution License (CC BY). The use, distribution or reproduction in other forums is permitted, provided the original author(s) and the copyright owner(s) are credited and that the original publication in this journal is cited, in accordance with accepted academic practice. No use, distribution or reproduction is permitted which does not comply with these terms. 